\title{
On the global ship hull bending energy in ship collisions
}

\author{
Pedersen, Preben Terndrup; Li, Yujie
}

Published in:

Marine Structures

Link to article, DOI:

10.1016/j.marstruc.2008.06.005

Publication date:

2009

Link back to DTU Orbit

Citation (APA):

Pedersen, P. T., \& Li, Y. (2009). On the global ship hull bending energy in ship collisions. Marine Structures, 22(1), 2-11. https://doi.org/10.1016/j.marstruc.2008.06.005

General rights

Copyright and moral rights for the publications made accessible in the public portal are retained by the authors and/or other copyright owners and it is a condition of accessing publications that users recognise and abide by the legal requirements associated with these rights.

- Users may download and print one copy of any publication from the public portal for the purpose of private study or research.

- You may not further distribute the material or use it for any profit-making activity or commercial gain

- You may freely distribute the URL identifying the publication in the public portal

If you believe that this document breaches copyright please contact us providing details, and we will remove access to the work immediately and investigate your claim. 


\title{
On the Global Ship Hull Bending Energy in Ship Collisions
}

\author{
Preben Terndrup Pedersen ${ }^{1}$ and Yujie $\mathrm{Li}^{1,2}$ \\ 1 Department of Mechanical Engineering, Technical University of Denmark, Building 403E, DK-2800 Lyngby, Denmark \\ 2 Chinese Ship Scientific Research Center, P.O. Box116, Wuxi, Jiangsu, 214082, P.R.China
}

\begin{abstract}
During ship collisions part of the kinetic energy of the involved vessels immediately prior to contact is absorbed as energy dissipated by crushing of the hull structures, by friction and by elastic energy. The purpose of this report is to present an estimate of the elastic energy that can be stored in elastic hull vibrations during a ship collision.
\end{abstract}

When a ship side is strengthened in order to improve the crashworthiness it has been argued in the scientific literature that a non trivial part of the energy released for structural deformation during the collision can be absorbed as elastic energy in global ship hull vibrations, such that with strong ship sides less energy has to be spent in crushing of the striking ship bow and/or the struck ship side.

In normal ship-ship collision analyses both the striking and struck ship are usually considered as rigid bodies where structural crushing is confined to the impact location and where local and global bending vibration modes are neglected. That is, the structural deformation problem is considered quasi-static. In this paper a simple uniform free-free beam model is presented for estimating the energy transported into the global bending vibrations of the struck ship hull during ship-ship collisions. The striking ship is still considered as a rigid body. The local interaction between the two ships is modeled by a linear loaddeflection relation.

The analysis results for a simplified model of a struck coaster and of a large tanker show that the elastic energy absorbed by the struck ship normally is small and varies from 1 to $6 \%$ of the energy released for crushing. The energy stored as elastic global hull girder vibrations depends on the ship mass, the local stiffness of the side structure, and of the position of contact.

Key words: ship collision, vibration, energy

\section{Introduction}

In Ref. [1] it is found that a crashworthy ship dedicated to transport of nuclear fuel waste can experience strong flexural vibrations due the large momentum which can be transferred to the two-node horizontal vibration mode. For minor collisions involving more traditional ships it may also be of interest to investigate which role transverse hull girder vibrations play in the absorption of the collision energy.

Theoretical analyses of ship-ship collisions fall into two categories. One category relies on simplified structural models where both the striking and the struck ship are considered to behave as rigid bodies 
and the structural deformation is concentrated at the impact point, see for instance Ref. [2] and [3]. The second category of analysis models the complete ship hull by a finite element method. Examples on this approach are Ref. [1], and [4] - [5]. With finite element analysis models it is possible to take into account the energy which is transferred to global transverse hull vibrations. But so far no systematic investigations seem to have been published on the role of elastic hull girder vibrations in ship collisions.

The objective of this note is to present a simplified method to estimate the magnitude of the kinetic deformation energy transferred from the striking vessel to the struck vessel and to present some general results. The struck ship is modeled as a uniform free-free Bernoulli-Euler beam. A linear relation between the load and the local deformation models the interaction between the two ships. The interaction between the colliding ship hulls and the surrounding water is modeled by simple constant added mass terms.

The applied mathematical model is extremely simple but should be able to give reliable qualitative results. The energy conservation law is used to check the numerical results. The numerical results to be presented include the effect of change of stiffness, the initial velocity of the striking vessel, the collision location, and the mass of the striking ship.

\section{Mathematical model}

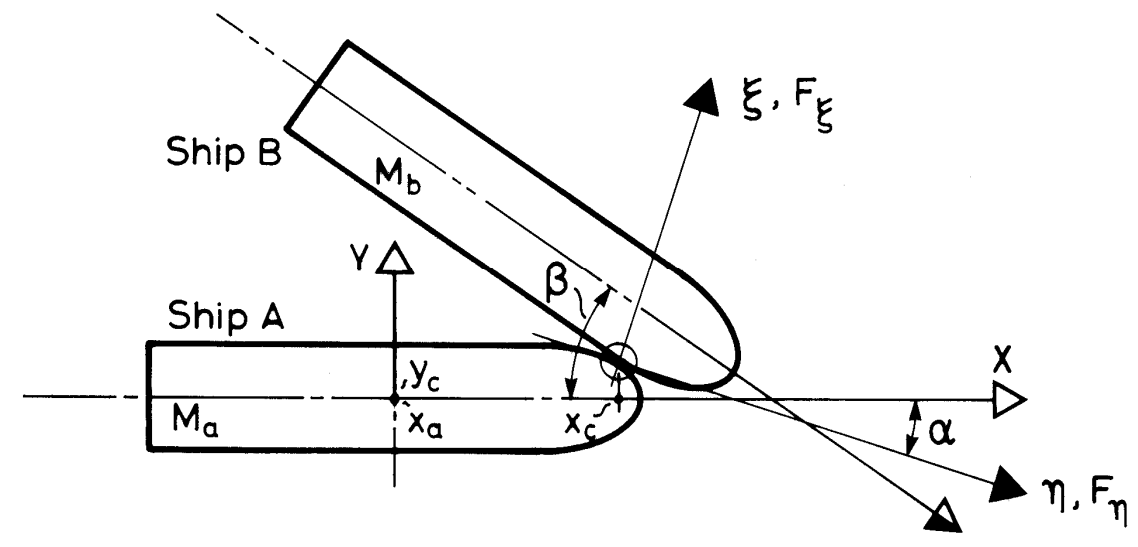

Fig. 1. Ship-ship collision and the coordinate system

For a rigid striking ship, $\mathrm{A}$, the equations of motion due to the impact force components $\mathrm{F}_{\xi}$ in the $\xi$ direction and $F_{\eta}$ in the $\eta$-direction, see Fig. 1, can be expressed as:

$$
\begin{aligned}
& M_{a}\left(1+m_{a x}\right) \&_{a x}=-F_{\xi} \sin \alpha-F_{\eta} \cos \alpha \\
& M_{a}\left(1+m_{a y}\right) \&_{a y}=-F_{\xi} \cos \alpha+F_{\eta} \sin \alpha \\
& M_{a} R_{a}^{2}\left(1+j_{a}\right) \&_{a}=F_{\xi}\left[y_{c} \sin \alpha-\left(x_{c}-x_{a}\right) \cos \alpha\right]+F_{\eta}\left[y_{c} \cos \alpha-\left(x_{c}-x_{a}\right) \sin \alpha\right]
\end{aligned}
$$


where $M_{a}$ is the mass of the striking ship, $\left(\mathbb{L}_{a x}, \mathbb{L}_{a y}, c_{a} \mathbb{a}\right)$ denote the accelerations of the striking ship in the $\mathrm{X}$ - and $\mathrm{Y}$-directions and the rotation around the center of gravity, respectively. The radius of the ship mass inertia around the center of gravity is $R_{a}$, the coordinate of the center of gravity of the striking ship is $\left(\mathrm{x}_{\mathrm{a}}, 0\right)$, the coordinate of the impact point is $\left(\mathrm{x}_{\mathrm{c}}, \mathrm{y}_{\mathrm{c}}\right)$, the added mass coefficient for the surge, sway and rotation motions are denoted $\mathrm{m}_{\mathrm{ax}}, \mathrm{m}_{\mathrm{ay}}, \mathrm{j}_{\mathrm{a}}$, respectively.

For the struck ship, bending vibrations are considered in the plane of the water surface. The structural behaviour of the struck ship is simply modeled by a linear uniform free-free beam. That is, longitudinal vibrations and shear deformations are neglected.

With these assumptions the motions of the struck ship can be expressed as

$$
\begin{aligned}
& M_{b}\left(1+m_{b 1}\right) \&_{b 1}=-F_{\xi} \sin (\beta-\alpha)+F_{\eta} \cos (\beta-\alpha) \\
& E I \frac{\partial^{4} y_{b 2}(x, t)}{\partial x^{4}}+C \frac{\partial y_{b 2}(x, t)}{\partial t}+\frac{M_{b}\left(1+m_{b 2}\right)}{L} \frac{\partial y_{b 2}{ }^{2}(x, t)}{\partial t^{2}}=\left(F_{\xi} \cos (\beta-\alpha)+F_{\eta} \sin (\beta-\alpha)\right) \delta\left(x_{0}\right)
\end{aligned}
$$

where $\mathrm{M}_{\mathrm{b}}$ is the mass of the struck ship, $\&_{\mathrm{b}}$ denotes the acceleration in the longitudinal $\mathrm{x}$-direction, $\mathrm{y}_{\mathrm{b} 2}(\mathrm{x}, \mathrm{t})$ denotes the transverse displacement of the struck ship, $\mathrm{x}_{0}$ is the position of the collision, $\mathrm{m}_{\mathrm{b} 1}$ and $m_{b 2}$ are the added mass coefficients for the surge and sway motions, respectively. The viscous damping coefficient is denoted C, E and I are Young's modulus and the area inertia moment around the vertical axis of the ship section, respectively, and $\delta\left(\mathrm{x}_{0}\right)$ is 1 when $\mathrm{x}=\mathrm{x}_{0}$ and 0 for other values of $\mathrm{x}$.

To solve the two sets of equations (1) and (2), we have to establish a relation between the collision force and the structural deformation. To continue with a simple model, we shall assume that the interaction force $\mathrm{F}(\mathrm{t})$ between the two ships is linear, i.e. the interaction force can be expressed as,

$$
F(t)=k\left(\left.y_{b 2}(x, t)\right|_{x=x_{0}}-x_{b 1}(t)\right)
$$

where $\left.y_{b 2}(x, t)\right|_{x=x_{0}}$ is the displacement of the struck ship at the collisions position, $\mathrm{x}_{\mathrm{b} 1}(\mathrm{t})$ is the displacement of the bow of the striking vessel, and $\mathrm{k}$ is a constant which expresses the combined stiffness of the side structure of the struck ship and the stiffness of the bow of the striking ship. The coefficient $\mathrm{k}$ can be estimated from crashworthy analyses of the involved ship structures.

Using an expansion in natural modes $\mathrm{y}_{\mathrm{r}}(\mathrm{x})$ for the transverse hull vibrations of the struck vessel, $\mathrm{y}_{\mathrm{b} 2}(\mathrm{x}$, t) can be expressed as

$$
y_{b 2}(x, t)=\sum_{r=0}^{\infty} y_{r}(x) \eta_{r}(t)
$$

For the free-free uniform beam model of the hull, the natural modes $\mathrm{y}_{\mathrm{r}}(\mathrm{x})$ are the two rigid body modes 


$$
\begin{aligned}
& \mathrm{y}_{0}(\mathrm{x})=\mathrm{A}_{0} \\
& \mathrm{y}_{1}(\mathrm{x})=\mathrm{A}_{1}(\mathrm{x} / \mathrm{L}-1 / 2)
\end{aligned}
$$

and the elastic modes

$$
\begin{gathered}
y_{r}(x)=A_{r}\left[\left(\cos \lambda_{r} L-\cosh \lambda_{r} L\right)\left(\sin \lambda_{r} x+\sinh \lambda_{r} x\right)-\left(\sin \lambda_{r} L-\sinh \lambda_{r} L\right)\left(\cos \lambda_{r} x+\cosh \lambda_{r} x\right)\right] \\
\mathrm{r}=2,3, \ldots
\end{gathered}
$$

where the eigenvalues $\lambda_{\mathrm{r}}$ are determined as solutions to the transcendental equation:

$$
\cos \lambda L \cosh \lambda L=1
$$

The natural modes can be made orthogonal and the constants $A_{r}(r=0,1,2, \ldots, n)$ are here chosen such that the modes represented by Eqs. (5) and (6) satisfy the orthogonality and normality condition:

$$
\int_{0}^{L} m y_{i} y_{j} d x=\delta_{i j}
$$

This results in the coefficients:

$$
\begin{array}{ll}
A_{0}=\frac{1}{\sqrt{m L}}, A_{1}=\sqrt{\frac{12}{m L}} & \\
A_{r}=\frac{1}{\sqrt{m L}} \frac{1}{\sin \lambda_{r} L-\sinh \lambda_{r} L} \quad, \mathrm{r}=2,3, \ldots
\end{array}
$$

If we substitute Eqs. (5) and (6) into the second equation of motion (2) for the struck vessel and assume that the damping coefficient $\mathrm{C}$ can be expressed as a linear combination of the stiffness and the mass terms in Eq. (2) we obtain the following set of uncoupled equations

$$
\oiint_{r}(t)+2 \xi_{r} \omega_{r} \oiint_{r}(t)+\omega_{r}^{2} \eta_{r}(t)=N_{r}(t) \quad, \mathrm{r}=0,1,2, \ldots, \mathrm{n}
$$

where $N_{r}(t)=\int_{0}^{L} y_{r}(x) f(x, t) d x$ represents the generalized force, $\xi_{r}(\mathrm{r}=0,1,2, \ldots)$ the damping factor, $\omega_{r}$ the circular natural frequency, and $\eta_{r}(t), \psi_{r}(t), \psi_{r}(t)$ are $\mathrm{r}^{\text {th }}$ generalized displacement, velocity and acceleration, respectively.

The kinetic energy of the beam can be expressed by the generalized velocities as 
$T(t)=\frac{1}{2} \int_{0}^{l} m(x)\left[\frac{\partial y(x, t)}{\partial t}\right]^{2} d x=\frac{1}{2} \sum_{r=0}^{\infty} 1 \&_{r}^{2}(t)$

The potential energy of the beam can be expressed as

$V(t)=\frac{1}{2} \int_{0}^{l} E I\left[\frac{\partial y(x, t)}{\partial x}\right]^{2} d x=\frac{1}{2} \sum_{r=0}^{\infty} \omega_{r}^{2} \eta_{r}^{2}(t)$

The bending moment $\mathrm{M}(\mathrm{x}, \mathrm{t})$ can be expressed as

$M(x, t)=E I \frac{\partial^{2} y(x, t)}{\partial x^{2}}=E I \sum_{r=2}^{\infty} \frac{d^{2} y_{r}(x)}{d x^{2}} \eta_{r}(t)$

where,

$\frac{d^{2} y_{r}(x)}{d x^{2}}=\frac{\lambda_{r}^{2}}{\sqrt{m L}}\left[\left(\cosh \lambda_{r} x-\cos \lambda_{r} x\right)-\frac{\cos \lambda_{r} L-\cosh \lambda_{r} L}{\sin \lambda_{r} L-\sinh \lambda_{r} L}\left(\sinh \lambda_{r} x-\sin \lambda_{r} x\right)\right]$

The global elastic bending strain in the ship side can be determined as

$\varepsilon(x, t)=\frac{B}{2} \frac{M(x, t)}{E I}$

where B is width of the hull beam.

Finally the stress is given by

$\sigma(x, t)=E \varepsilon(x, t)$

\section{Numerical solution procedure}

A rough estimate of the energy fraction transmitted to transverse hull bending vibrations of the struck ship will be sought here. Therefore, we shall in the following only consider right angle transverse collisions where the coupling between the axial rigid body motions and the bending vibrations can be neglected. Hence $\alpha=\beta=\pi / 2$ and $F_{\xi}=-F(t)$ and the equations of motion for the striking and the struck vessel can be simplified to

$$
\begin{aligned}
& M_{a}\left(1+m_{a}\right)=F(t) \\
& E I \frac{\partial^{4} y_{b 2}(x, t)}{\partial x^{4}}+C \frac{\partial y_{b 2}(x, t)}{\partial t}+\frac{M_{b}\left(1+m_{b 2}\right)}{L} \frac{\partial y_{b 2}{ }^{2}(x, t)}{\partial t^{2}}=-F(t) \delta\left(x_{0}\right)
\end{aligned}
$$


where is the surge acceleration of the striking vessel.

We will furthermore assume that the struck ship is at rest at the beginning of the collision. That is

$y_{b 2}(x, t)=\&_{b 2}(x, t)=0$, at $\mathrm{t}=0$

The initial velocity of the striking ship is $\mathrm{V}_{0}$, then at time $t=\Delta t$, the forward position of the striking ship is given by

$x_{a 1}(\Delta t)=V_{0} \Delta t$

With a linear relation between the force and the displacement the collision force becomes

$\mathrm{F}(\Delta \mathrm{t})=-\mathrm{k} \mathrm{V}_{0} \Delta \mathrm{t}$

This enables us to compute a first estimate of the displacement of the struck vessel $\mathrm{y}_{\mathrm{b} 2}(\mathrm{x}, \Delta \mathrm{t})$ by use of the equation of motion (4) and (7) for the struck vessel, where the ordinary differential equations (7) are solved by a standard numerical integration technique.

In the next time step the force is given by

$\mathrm{F}(2 \Delta \mathrm{t})=\mathrm{k}\left(\mathrm{y}_{\mathrm{b} 2}\left(\mathrm{x}_{0}, \Delta \mathrm{t}\right)-\mathrm{x}_{\mathrm{a} 1}(\Delta \mathrm{t})\right)$

where the displacement of the striking ship is given by

$x_{a 1}(\Delta t)=2 x_{a 1}(\Delta t)-x_{a 1}(0)-\left[\Delta t^{2} F(\Delta t)\right] / M_{1}$

This forward stepping process is stopped when the relative velocity at the collision point of the two ships is zero. This ends the collision phase. The free response of the struck ship is still computed after setting the collision force to zero.

\section{Calculation results}

The procedure described above has been applied to two different struck vessels. The first vessel is a tanker which previously has been subjected to intensive collision analysis, see Lützen et al [7]. The second example is the general cargo vessel considered in the CRASHCOASTER project, see Pinkster et al (2000). The main parameters of these struck ships are shown in Table 1. The added mass coefficients are taken as 0.05 for the surge motion, 0.85 for the sway motion.

Table1 Dimensions of the vessels

\begin{tabular}{|l|l|l|}
\hline & Tanker & $\begin{array}{l}85 \mathrm{~m} \text { Box Hold } \\
\text { Coaster }\end{array}$ \\
\hline Length & $240.0 \mathrm{~m}$ & $84.98 \mathrm{~m}$ \\
\hline Breadth & $42.0 \mathrm{~m}$ & $13.6 \mathrm{~m}$ \\
\hline Draught & $21.0 \mathrm{~m}$ & $5.7 \mathrm{~m}$ \\
\hline
\end{tabular}




\begin{tabular}{|l|l|l|}
\hline Displacement & $105400 \mathrm{t}$ & $4228 \mathrm{t}$ \\
\hline
\end{tabular}

For the tanker the hull structural moment of inertia about a vertical axis is calculated as $1172.4 \mathrm{~m}^{4}$. The damping coefficient is assumed to be 0.01 for all modes. The combined local stiffness of the colliding bow and the side structure is varied between 10 to $100 \mathrm{MN} / \mathrm{m}$.

The natural frequencies of the first 5 modes are 1.079, 2.974, 5.829, 9.636, 14.39Hz, respectively.

Three impact positions have been considered: Aft end (position 0), L/4 from aft (position 1/4) and amidship (position $1 / 2$ )..

The influence of the mass of the striking vessel is also examined.

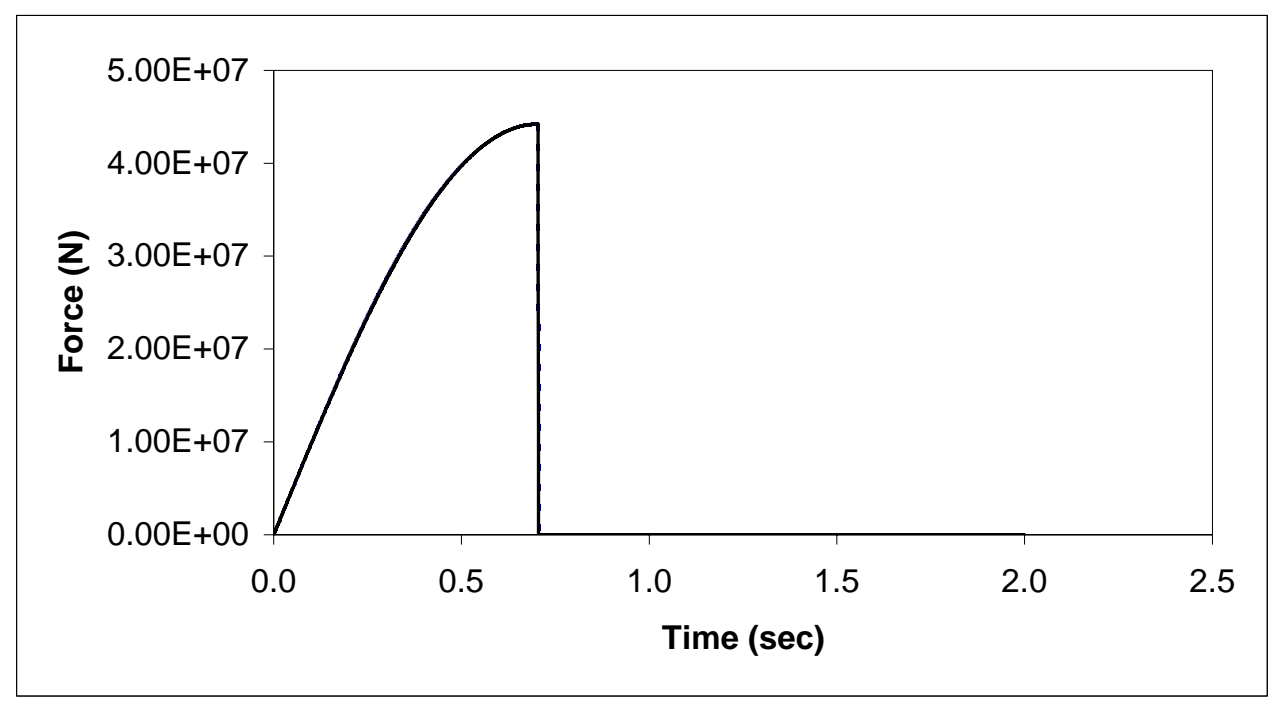

Fig.2. Calculated collision force-time curve with collision position is amidship.

Initial velocity of the striking ship is $V_{0}=2 \mathrm{~m} / \mathrm{s}$. Local stiffness coefficient $k=50 \mathrm{MN} / \mathrm{m}$

A typical variation of the collision force with time is shown in Fig. 2, for a case where the combined stiffness parameter $\mathrm{k}=50 \mathrm{MN} / \mathrm{m}$, the initial velocity of the striking ship $\mathrm{V}_{0}=2 \mathrm{~m} / \mathrm{s}$, and the mass of the striking ship is $10,000 \mathrm{t}$.

For a given initial velocity of the striking vessel, the maximum collision force increases as the local stiffness $\mathrm{k}$ increases. This is illustrated in Fig. 3, where results are shown for a case with $\mathrm{V}_{\mathrm{o}}=2 \mathrm{~m} / \mathrm{s}$ and where the striking ship is similar to the struck tanker with main particulars given in Table 1 . 


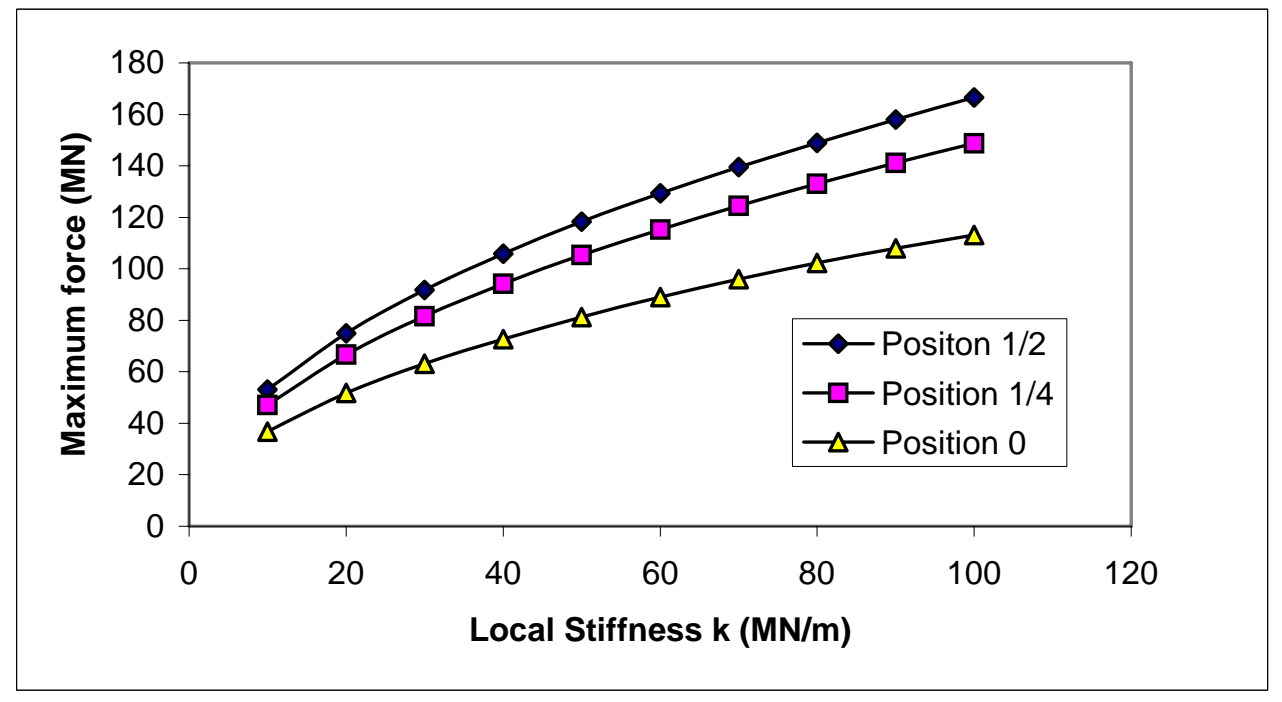

Fig. 3. Maximum collision force versus local stiffness for three different collision positions (position 0, 1/4,1/2 is defined as the ratio between the distance $x$ measured from the end of the struck ship and the struck ship length $L$ )

For a constant local stiffness $\mathrm{k}$, the maximum collision force increases linearly with the initial velocity of the striking ship. We also note that when the collision position is located at the end of the struck ship the collision force is obviously smaller than when the collision happens near amidship. This due to the influence of the rotation of the struck ship.

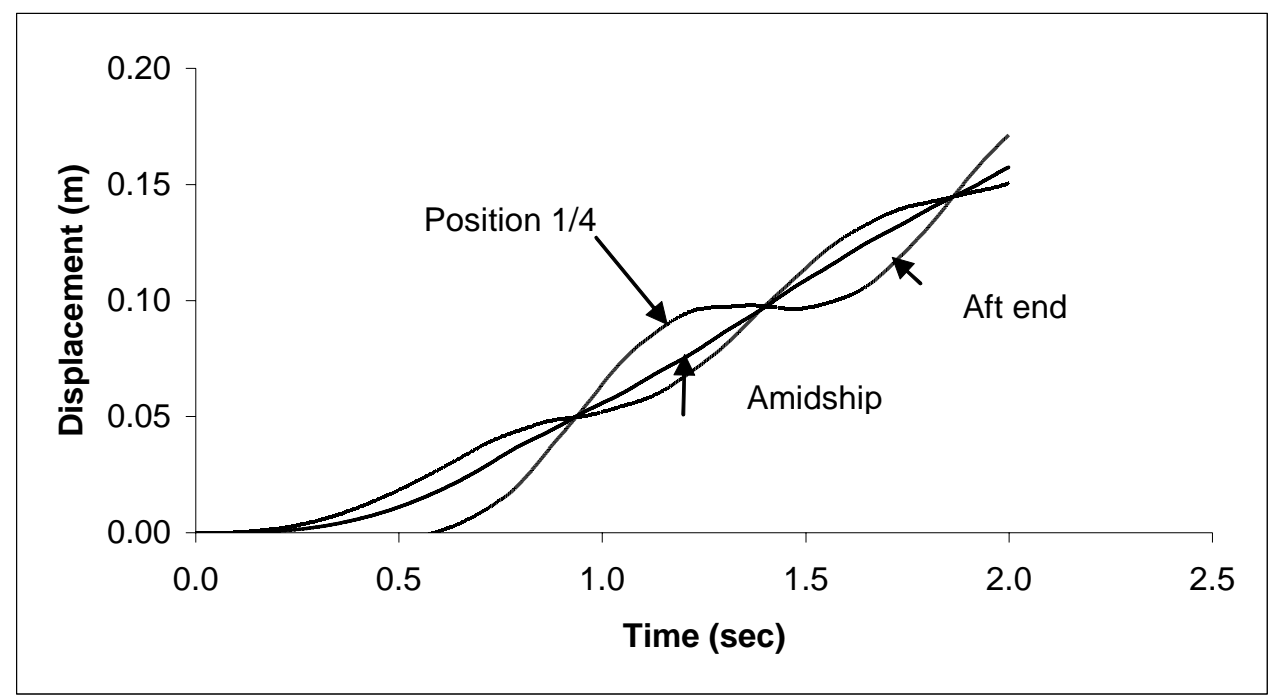

Fig. 4. The displacement-time curve at three different positions of the struck ship, the impact position is at the middle of the struck ship 


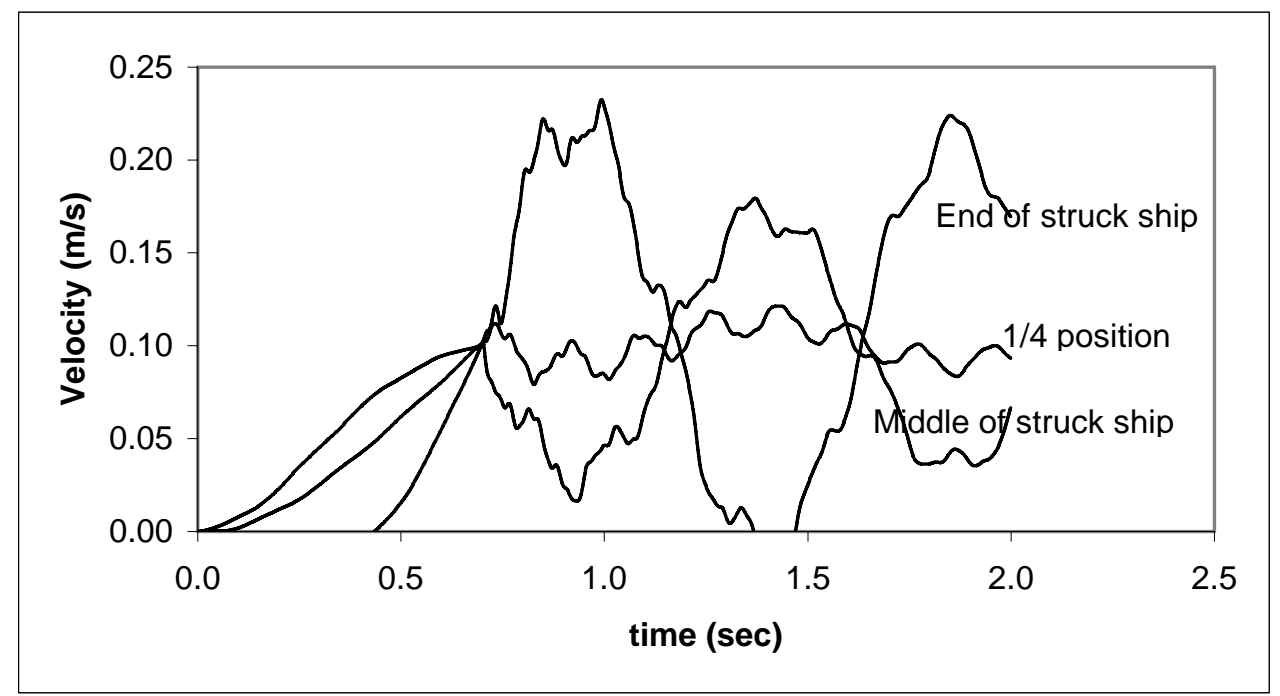

Fig. 5. The velocity-time curve at three different positions of the struck ship, the impact point is at the middle of the struck ship

A set of response curves is shown in Fig. 4 and Fig. 5, corresponding to $\mathrm{k}=50 \mathrm{MN} / \mathrm{m}, \mathrm{V}_{0}=2 \mathrm{~m} / \mathrm{s}$, and $\mathrm{M}_{1}=10,000 \mathrm{t}$. These figures show the displacement and velocity at three different positions on the struck ship when the collision position is located at the middle of the ship. The displacement is mainly related to the rigid body motion. The velocity increases during the collision stage at the middle part of the ship, but at the end of the ship there is an opposite motion at the beginning of the collision. When the collision is over, the two-node vibration mode is clearly seen.

The energy conservation law is used to check the numerical results. The kinetic energy of the striking ship, the crushing energy absorbed by the bow and the side structure, the kinetic energy and the energy stored in elastic hull vibrations are shown in Fig. 6 . These curves indicate that the calculated results are quite accurate. 


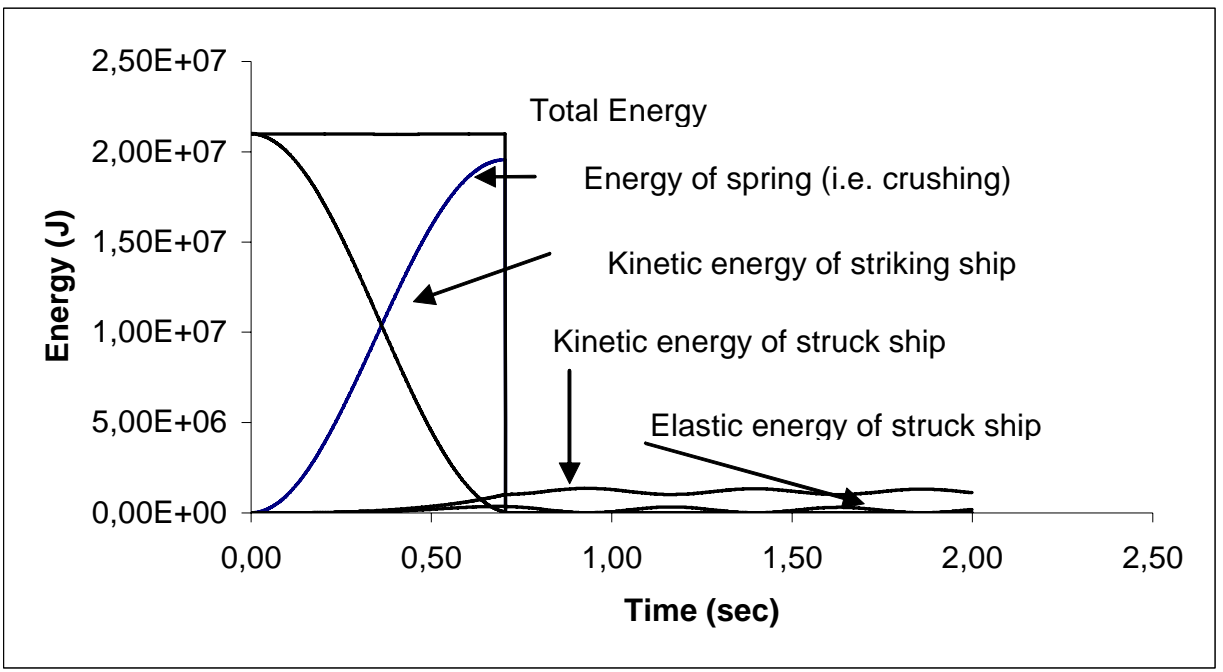

Fig. 6. Energy balance during ship-ship collision

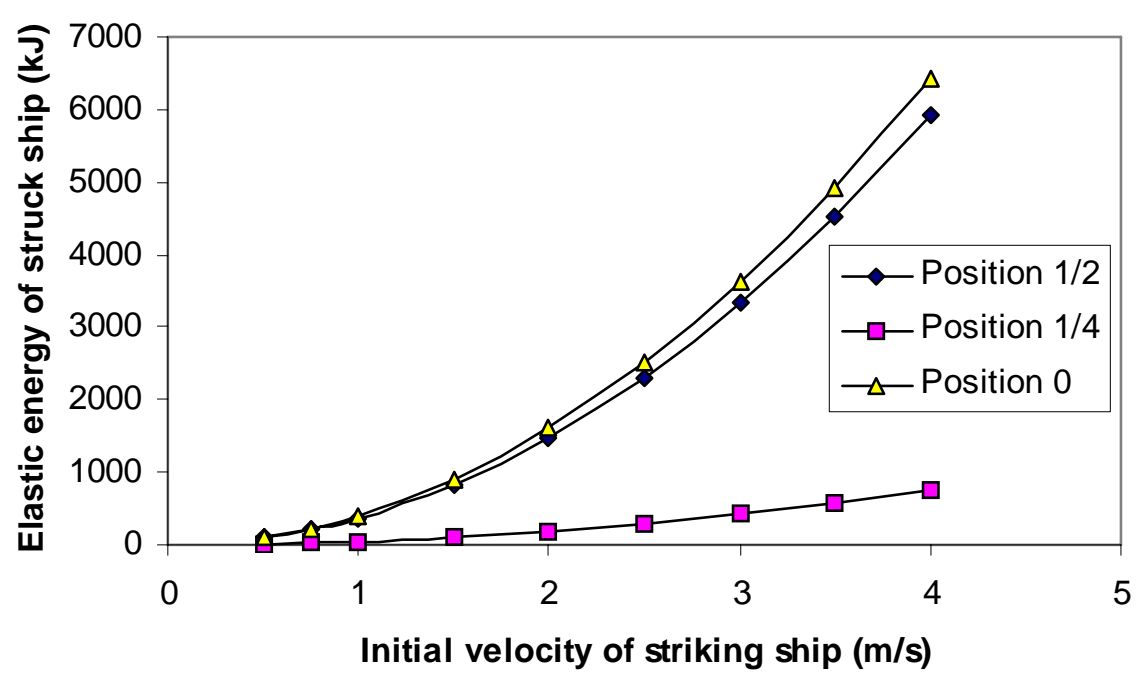

Fig.7. Elastic vibration energy of struck ship versus initial velocity of striking vessel for three different collision positions.

The elastic energy distribution versus the initial velocity for the three different collision positions is shown as Fig.7, where the calculation conditions are the same as those used for Fig. 3. It is seen that when the collision positions are located close to the middle and the end of the ship, the maximum elastic energy stored in the struck ship is nearly the same. However, when the collision position is located at the quarter length position of the ship, the elastic energy is very small. This is due to the fact that this collision position is close to a node point of the two-node vibration mode. 


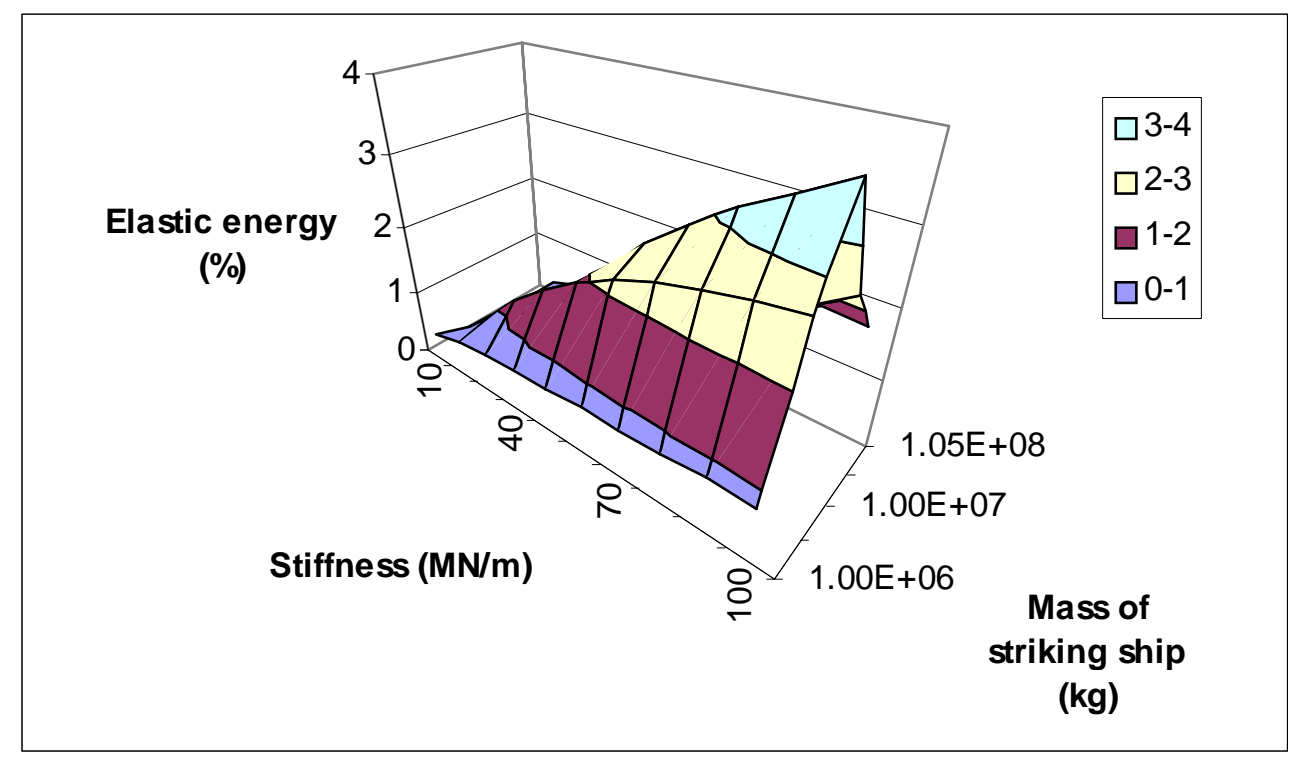

Fig. 8. The global elastic vibration energy in the tanker hull as percentage of the energy released for crushing as function of the local stiffness and the mass of the striking ship

Figure 8 shows the elastic energy stored in global ship hull vibrations of the struck vessel as percentage of the energy released for crushing of the bow of the striking vessel and/or crushing of the side structure of the struck vessel. It is seen that for the tanker structure this ratio normally will be below $3 \%$.

A similar set of calculations have been performed for the coaster. Here Fig. 9 shows that for a midship collision the vibration energy which can be stored in the struck vessel can be up to $6 \%$ of the energy released for local crushing. 


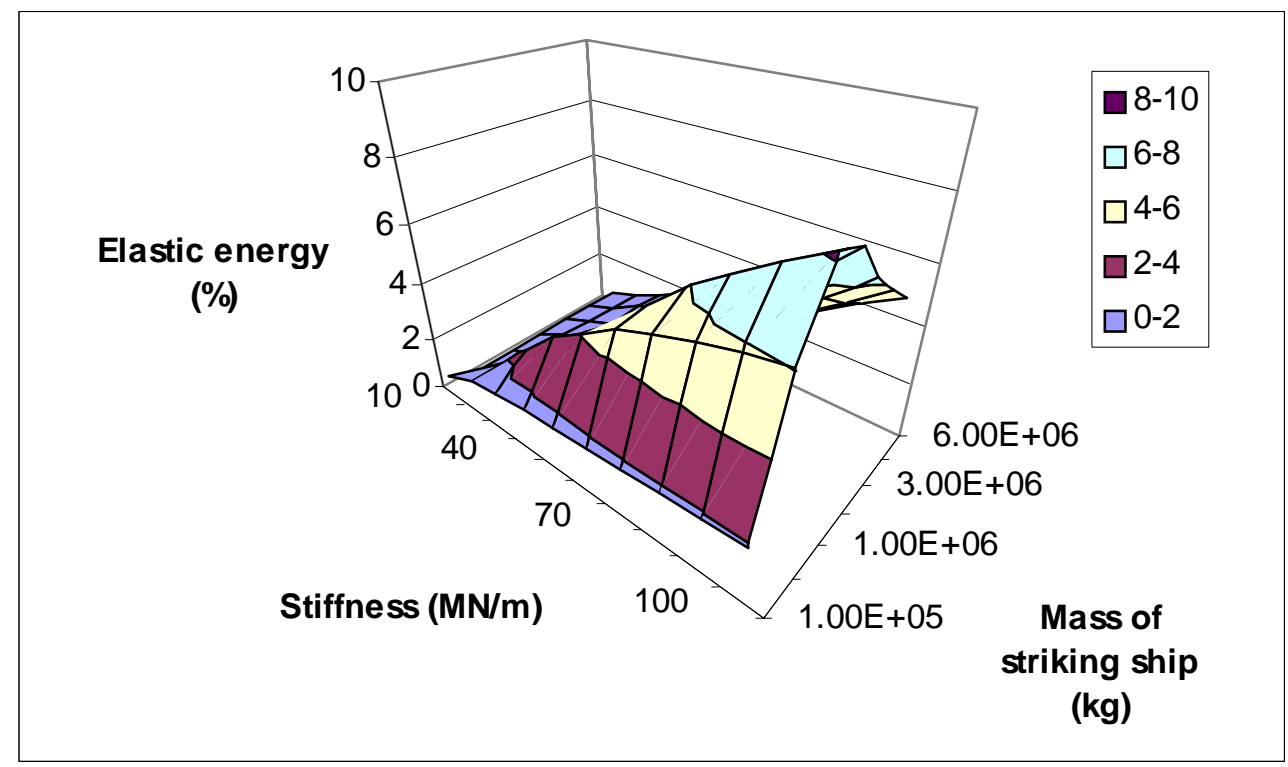

Fig. 9. The elastic hull vibration energy as percentage of local deformation energy for midship collision for a coaster as function of the local stiffness and the mass of the striking ship

Figure 10 shows that the fraction of energy stored in global vibrations of the coaster for a right angle collision at the ends of the vessel can go up to around 25 percent of the crushing energy. However, it should be noted that for an end collision the energy released for crushing is relatively small due to the energy dissipated by rigid body rotation of the struck vessel.

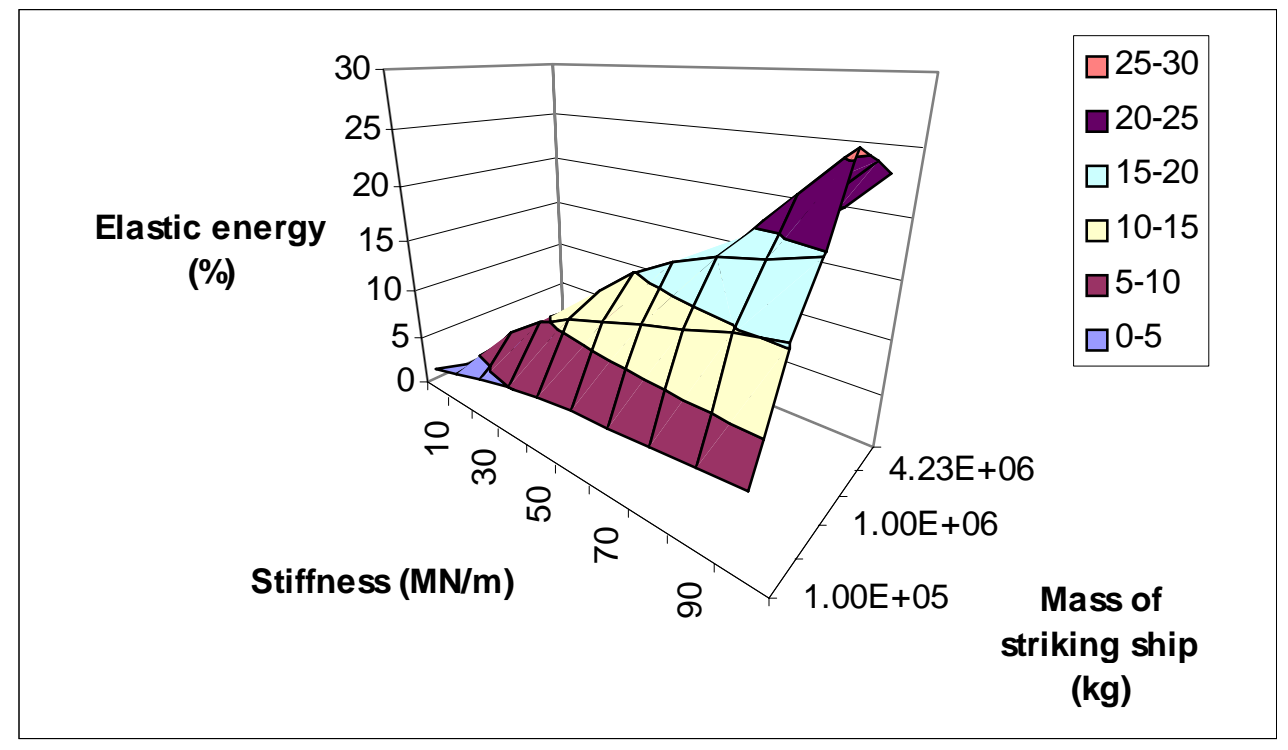

Fig. 10. The elastic hull vibration energy as percentage of local deformation energy for end collision on a coaster as function of the local stiffness and the mass of the striking ship 
Finally, it could be of interest to investigate whether the bending strains and stresses in the struck ship hull can be of such a magnitude, that the hull can be damaged in bending. From Figs. 11 and 12 it is seen that for both the tanker and the coaster the maximum global strains become quite high if the local stiffness at the collision point is large and the vessels at the same time are hit by ships with large masses.

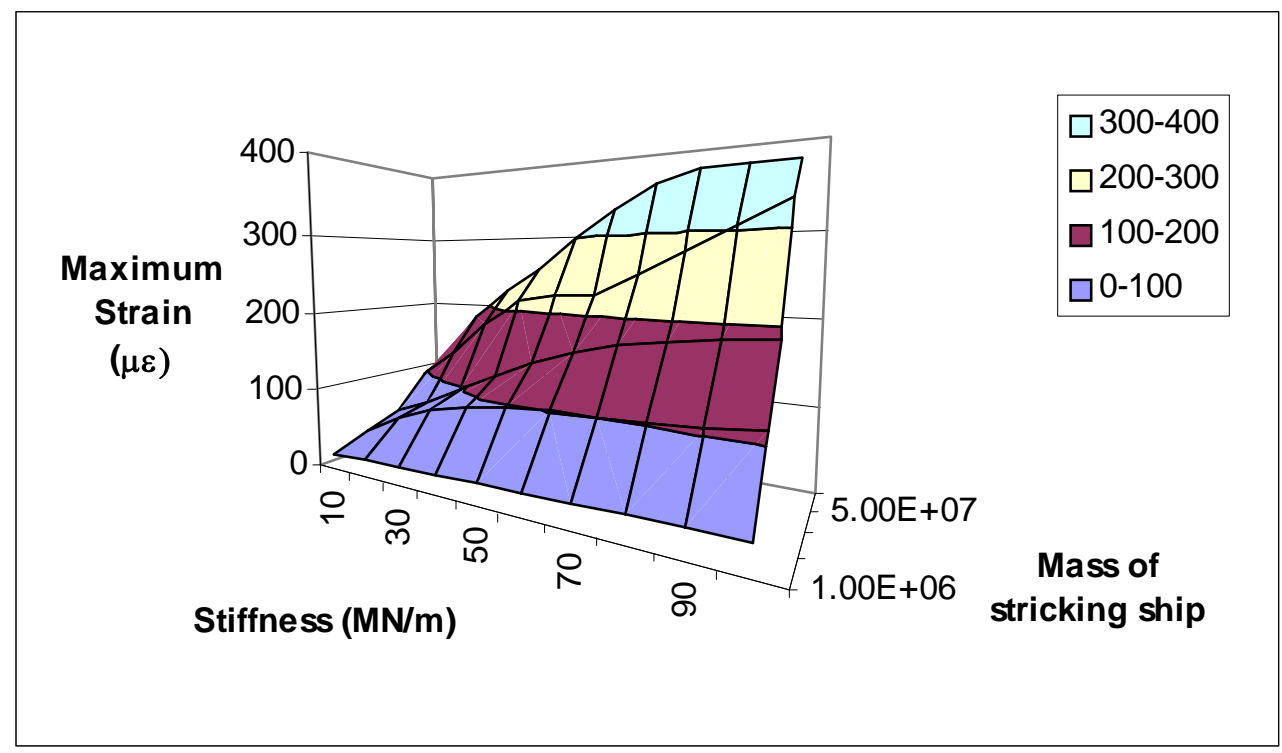

Fig. 11. The maximum strain as function of the local stiffness and the mass of the striking ship (Tanker hit amidship by striking vessel with $2 \mathrm{~m} / \mathrm{s}$ )

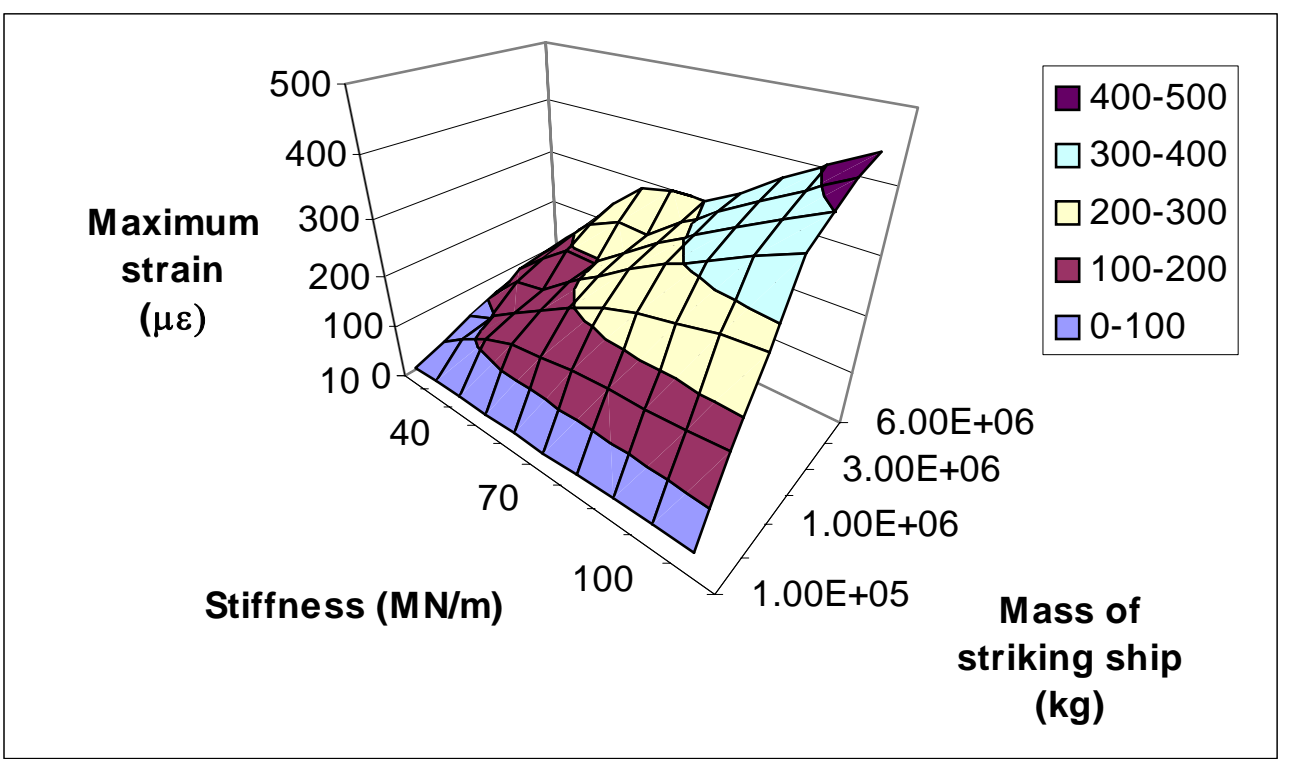

Fig. 12. The maximum strain as function of the local stiffness and the mass of the striking ship (Coaster hit amidship by striking vessel with $2 \mathrm{~m} / \mathrm{s}$ ) 


\section{Conclusion}

A simplified model for estimating the vibration energy of a struck ship during a ship collision is developed in this paper. Some numerical results are presented which shows that the elastic energy of the struck ship is relatively small and usually only a few percent of the energy released for structural crushing and friction.

The results also show that the maximum bending stresses during the global ship hull vibrations can become so high that bending damage of the ship hull can be expected if the side structure is locally stiffened in order to prevent or minimize local collision damage to the struck vessel such as is the case fo vessels for transportation of nuclear waste.

\section{Acknowledgement}

The present research was partly funded by the European Commission under the BriteEuRam programme: Crashworthy Side Structures in Short Sea Shipping (Crashcoaster) project (GRD1-199910566). The partners were TNO Building and Construction Research, Centre for Mechanical Engineering (TNO), Estaleiros Navais de Viana do Castelo, SA (ENVC), Bodewes Scheepswerf "Volharding" Foxhol BV (BOD), Flensburger Schiffbau Gesellschaft mbh\&Co.Kg (FSG), Chantiers d'Atlantique (CAT), United European Car Carriers AS (UECC), Wagenborg Shipping BV (WAG), Germanischer Lloyd (GL), Bureau Veritas (BV), Technical University of Denmark (DTU), Delft University of Technology (DUT), and Instituto Superior Tecnico (IST).

\section{References}

1. Kitamura, Ou and Endo, Hisayoshi: "Collision Simulations of an Exclusive Ship of Spent Nuclear Fuels", International Workshop on Utilization of Nuclear Power in Oceans, Feb.21-24, 2000 Toranomon Pastral Tokyo, Japan

2. Pedersen, P. Terndrup: "Collision and Grounding Mechanics", Proceedings WEMT'95, Editors Jensen and Jessen, 17-19 May, 1995, Copenhagen, pp.134-139,

3. Zhang, S: "The Mechanics of Ship Collisions", Ph.D thesis, Technical University of Denmark, Jan. 1999

4. A. Glykas, and P.K. Das "Energy Conservation during a Tanker Collision", J. of Ocean Engineering, 28 (2001), 361-374

5. A. Glykas, and P.K. Das, "Energy Conservation during Grounding with Rigid Slopes”, J. of Ocean Engineering, 28 (2001), 361-374

6. Pedersen, P. Terndrup and Simonsen, B. Cerup:” Dynamics of Ship Running Aground", J. Mar Sci. Technology (1995) 1: 37-45 
7. Lützen, M.; Pedersen, P. Terndrup and Simonsen, B. Cerup: "Rapid Prediction of Damage to Struck and Striking Vessels in a Collision Event” Proc. Ship Structure Symposium 2000, Society of Naval Architects and Marine Engineers, Washington D.C., June 2000.

8. Vredevelt, A.W: "Crashworthiness as means to improve damage stability survivability" Proc. $2^{\text {nd }}$ Int. Conf. on Collisions and Grounding of Ships. Eds.: Lützen, Simonsen, Pedersen and Jessen, pp 311- 318. Copenhagen July 2001.

9. Wang, Ge; Arita, K.; Liu, D.: "Behavior of a Double Hull in a Variety of Stranding or Collision Scenarios”, J. of Marine Structures, 13 (2000),147-187 